\title{
Ultrasensitive and selective non-enzymatic glucose detection based on pt electrode modified by carbon nanotubes@graphene oxide/ nickel hydroxide- Nafion hybrid composite in alkaline media
}

\author{
Sirous Mohammadi ${ }^{\mathrm{a}}$, Alireza Taheri (10) $\mathrm{a},{ }^{*}$ Zeinab Rezayati-zad (i) b \\ a Department of Chemistry, Islamic Azad University, Ilam branch, Ilam, Iran \\ $b$ Department of Food and Drug, Faculty of Medicine, Ilam University of Medical Sciences, Ilam, Iran
}

\section{H I G H L I G H T S}

- A novel glucose sensor has been fabricated by carbon nanotubes and graphene oxide.

- The sensor has high stability, wide linear dynamic range, low detection limit, high sensitivity.

- The biosensor was used in human blood serum and the oxidant with satisfactory results.

\section{A R T I C LE I N F O}

Article history:

Received: 2018-Sep-9

Accepted: 2018-Oct-1

Available online: 2018-Oct-30

Manuscript ID: PCBR-1810-1000

\section{Keywords}

$\mathrm{Ni}(\mathrm{OH})_{2}$ nanoparticles Activated Carbon nanotubes

Nafion

Glucose sensor graphene oxide

\section{GR A P H I C A L A B S T R A C T}

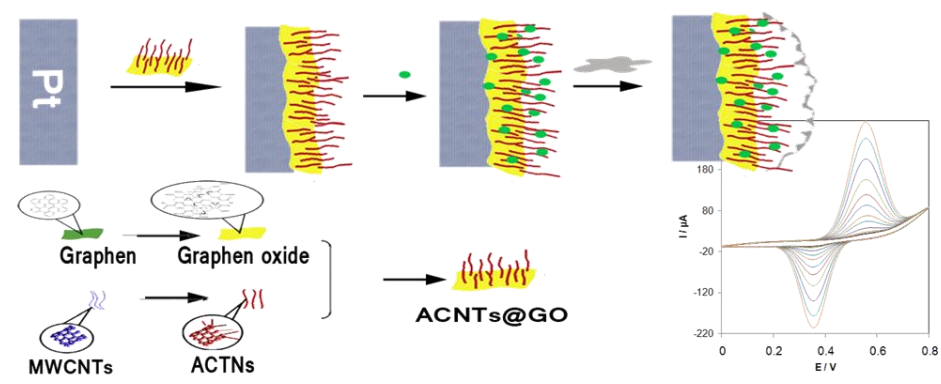

\begin{abstract}
A B S T R A C T
A new enzymeless glucose sensor has been fabricated and its electrocatalytic oxidation has been investigated in alkaline medium directly on the Pt Electrode modified by Activated carbon nanotubes @ graphene oxide/ nickel hydroxide-Nafion hybrid composite (Pt \ACNT@GO \NHNPs \Nf). Under the optimized condition, the calibration curve is linear in the concentration range of 5-1100 $\mu \mathrm{M}$ using cyclic voltammetric method. The detection limit and sensitivity are $0.75 \mu \mathrm{M}$ and $40 \mathrm{nA}$, respectively. The glucose sensor can be renewed easily in a reproducible manner by a simple polishing step and it has a long operational lifetime and short response time t90\%<1 s. In addition, the fabrication of Pt with nafion and nickel hydroxide powder was employed to eliminate the interference of ascorbic acid during the catalytic oxidation of glucose. The biosensor was used for determination of glucose in human blood serum and the oxidant with satisfactory results.
\end{abstract}

\section{Introduction}

Sensitive and selective glucose sensors are not only relevant for use in blood sugar monitoring, but also in the food industry, bio-processing and in the development of renewable, sustainable fuel cells [1]. Carbon nanotubes (CNTs) and graphene oxide (GO) can be used as a suitable intermediate between electrodes and enzymes. Recently, they have been used in various areas, such as biosensors and bio-fuel cells, because of their high surface area, high surface/volume ratio, good electrical conductivity and significant mechanical strength. Moreover the film formed by these materials has the advantages of high organization and uniformity, which could provide a desirable microenvironment and facilitate the direct electron transfer to the underlying electrode [2-4]. 
Graphene oxides are conducive to combine with aromatic molecules through p-p interaction, which are different with graphene and CNTs. Moreover, Graphene oxides have abundant edges, thus exhibiting electrocatalytic activity $[5,6]$.

Moreover, the physical and electrochemical properties of Carbon nanotubes composite graphene can be significantly enhanced through electrochemical activation by increasing the active area of electrode surface [7]. Also, electrochemical activation increases the electrical conductivity by generating active sites on the electrode surface. Thereby motivated, we expected that activated carbon nanotubes @ graphene oxide (ACNT@GO) could also introduce more active sites into the nanocomposite structure and provide a path for rapid electron transport, with high electric conductivity and specific surface areas. Therefore, they may be excellent support material for grafting MIPs on the surface.

Transition-metal nanoparticles, in different forms, have emerged as a novel family of catalysts able to promote more efficiently a variety of organic transformations because of their small size and extremely large surface-tovolume ratio [8, 9]. some nanoparticles have been successfully introduced onto MWCNTs, such as $\mathrm{Au}[10$, 11], $\mathrm{Cu}$ [12] and Ag [13]. Many electrodes were modified by $\mathrm{Ni}, \mathrm{NiO}_{2}, \mathrm{Ni}(\mathrm{OH})_{2}$ particles and nanoparticles on traditional electrode surfaces such as diamond [14], gold [15], carbon or graphite [16]. In contrast to $\mathrm{Ni}$ nanomaterials which are unstable and easily oxidized in air and solution, hydroxide (or oxide) of this material is relatively stable [17]. Nickel hydroxide nanoparticles (NHNPs) with a small crystalline size show a high proton diffusion coefficient, giving excellent electrochemical performance.

The method of homogeneous precipitation is new and facile, needing no expensive raw materials or equipment, it is also easy for mass production, and can be extended to synthesize other hydroxide or oxide nanocrystals. Nafion (Nf) has been widely reported as an immobilization matrix for the preparation of biosensor and bioreactor, which exhibits excellent film forming ability with the properties of biocompatible, biodegradable and nontoxic. due to its easy fabrication, good electrical conductivity, high chemical stability and good biocompatibility, it has been widely used as a protective coating material and as a support for enzyme immobilization [18].

Our experiments showed that use of Activated multi walled carbon nanotubes (ACNT) and graphene oxide (GO) composite film for modification of the Pt electrode would increase the charge transfer rate greatly. Herein, we took the advantages of electrocatalytic activity of
NHNPs and the advantages of nafion film to construct glucose biosensors through an electrochemical process strategy at high potential.

\section{Experimental}

\subsection{Reagents and solutions}

The multiwalled carbon nanotubes (MWCNTs) of 20-30 $\mathrm{nm}$ in diameter and 0.5-2.0 $\mu \mathrm{m}$ in length; purity: $\geq 95 \%$, were purchased from Sigma. Graphene (KNG-CZ030) was purchased from KNANO (Xiamen, China). Nafion (Nf) (5 wt\% solution in a mixture of lower aliphatic alcohols and water) was obtained from Aldrich. D -(+)-glucose was purchased from Sigma-Aldrich Co. Buffer solution (0.1 M) was prepared from $\mathrm{H}_{3} \mathrm{PO}_{4}$, $\mathrm{Na}_{2} \mathrm{HPO}_{4}, \mathrm{NaH}_{2} \mathrm{PO}_{4}, \mathrm{HNO}_{3}, \mathrm{H}_{2} \mathrm{SO}_{4}, \mathrm{NaOH}$ and $\mathrm{HCl}$ for the $\mathrm{pH}$ range $1-13$.

Fresh human serum samples were available from Razi Institute of Vaccine and Serum Company (Tehran, Iran). Glucose $(30 \% \mathrm{w} / \mathrm{w})$ was from Merck, its diluted solution was prepared daily. All solutions were prepared with double distillated water. Pure $\mathrm{N}_{2}$ was passed through the solution to avoid possible oxygen action during the experiments.

\subsection{Preparation of graphene oxide}

Graphene (1.5 g), $\mathrm{HNO}_{3}(75 \mathrm{~mL})$ and $\mathrm{H}_{2} \mathrm{SO}_{4}(75 \mathrm{~mL})$ were added into conical flask and stirred at room temperature for $12 \mathrm{~h}$. Next, the mixing system was transferred to the oil bath with stirring at $140{ }^{\circ} \mathrm{C}$ for 90 min. Finally, the product was filtered and washed with deionized water to $\mathrm{pH}=7$ and dried in a vacuum for $24 \mathrm{~h}$, and the graphene oxide was obtained.

\subsection{Preparation of activated CNTS}

The electric conductivity of carbon nanotubes are easily influenced because they are hydrophobic and tend to reaggregation without physical or chemical functionalization.

Their low solubility also restricts from being a modification material to elevate the peak current. MWCNTs (2.0 g) and HNO3 (100 mL) were added into conical flask and heated with stirring at $90{ }^{\circ} \mathrm{C}$ for $6 \mathrm{~h}$. After the mixture was cooled down to room temperature, it was filtered and washed with deionized water until the solution $\mathrm{pH}$ was neutral and dried in a vacuum for $24 \mathrm{~h}$, and the activated MWCNTs (ACNT) was obtained. 


\subsubsection{Preparation of activated CNTs- graphene oxide (ACNT@GO)}

Briefly, graphene oxide was obtained by treating graphene with $\mathrm{HNO}_{3}$ and $\mathrm{H}_{2} \mathrm{SO}_{4}$. The ACNT was adsorbed onto the surface of graphene Oxide (GO) through $\pi-\pi$ attractions to obtain the graphene oxide and ACNT hybrid composite. Therefore $1.0 \mathrm{~g}$ of GO and $1.0 \mathrm{~g}$ of ACNT $1.0 \mathrm{~g}$ were dispersed in $10 \mathrm{~mL}$ deionized water at $35{ }^{\circ} \mathrm{C}$ temperature for $12 \mathrm{~h}$.

\subsection{Synthesis of NHNPS}

Nickel hydroxide nanoparticles (NHNPs) was synthesized using a coordination precipitation procedure as previously reported [19]. Briefly, by adding concentrated ammonia (28wt.\%) to nickel nitrate solution (1 M), a deep blue colored nickel hexamine complex solution was formed and added into a given amount of distilled water, the reaction was carried out under magnetic stirring for $1 \mathrm{~h}$ at $70{ }^{\circ} \mathrm{C}$. Finally, light green sediments were formed. The precipitate was separated by centrifuge and rinsed with distilled water and ethanol three times respectively to remove the adsorbed ions, then dried in a vacuum oven at $85^{\circ} \mathrm{C}$ for $13 \mathrm{~h}$; the final product was green powder. Product that is obtained without any surfactant in the reaction process was platelet-like shape. The method is simple and facile; it is low cost and also easy for mass production and can be extended to synthesize other hydroxide or oxide nanocrystals.

\subsection{Preparation of the glucose solution}

A glucose stock solution $(0.5 \mathrm{M})$ was prepared in a $0.1 \mathrm{M}$ phosphate buffer solution $(\mathrm{pH} 7.0)$ then left at room temperature for about $24 \mathrm{~h}$ prior to use to ensure the presence of the $\beta$-d-glucose form.

\subsection{Instrumentation}

All the voltammetric measurements were carried out using Pt $\backslash A C N T @ G O \backslash N H N P s \backslash N f$ as the working electrode, $\mathrm{Ag} / \mathrm{AgCl}, 3 \mathrm{M} \mathrm{KCl}$ as the reference electrode and platinum wire as an auxiliary electrode. Electrochemical measurements were performed using a $\mu$ AUTOLAB TYPE III (Eco-Chemie B.V., Utrecht, and The Netherlands).

\subsection{Fabrication of glucose biosensor}

Prior to use, the Pt electrode ( $2 \mathrm{~mm}$ in diameter) was first polished with alumina slurry (followed by $1.0 \mu \mathrm{m}$ and
$0.05 \mu \mathrm{m}$ ) on microcloth pads followed by ultrasonically cleaning with 1:1 water, ethanol and distillated water and then electrochemically pretreated by potential cycling between 0.0 and $1.0 \mathrm{~V}$ in an alkaline solution until steady background curves were obtained. $20 \mu \mathrm{L}$ of prepared suspension of ACNT@GO was casted on the electrode with a microsyring. The electrode was dried in air, denoted as Pt\ACNT@GO. A stock solution of NHNPs in ethanol was prepared by dispersing $2 \mathrm{~g}$ of NHNPs in $10 \mathrm{~mL}$ ethanol using ultrasonic bath until a homogeneous solution resulted, and $1 \mu \mathrm{L}$ of prepared suspension was casted on the electrode and dried in air. After that, $10 \mu \mathrm{L}$ of $\mathrm{Nf}(5$ wt.\%) solution was casted on the surface of the electrode and was set in ultrasonic bath to form a stable composite film. The fabricated electrode was denoted as Pt $\backslash A C N T @ G O \backslash N H N P s \backslash N f$ and stored at $4{ }^{\circ} \mathrm{C}$ when not in use. Fig. 1 shows the Schematic illustration of stepwise Electrode modification.

\subsection{General procedure}

$10 \mathrm{~mL}$ solution containing appropriate amounts of glucose in $0.5 \mathrm{M} \mathrm{NaOH}$ was transferred into the voltammetry cell. Calibration curves were obtained by plotting the anodic peak currents of glucose against the corresponding concentrations. All experiments were carried out under open circuit conditions. After each measurement, the electrode was regenerated by thoroughly washing the electrode with distilled water. The electrode was finally rinsed carefully with distilled water to remove all adsorbate from electrode surface and provide a fresh surface for next experiment.

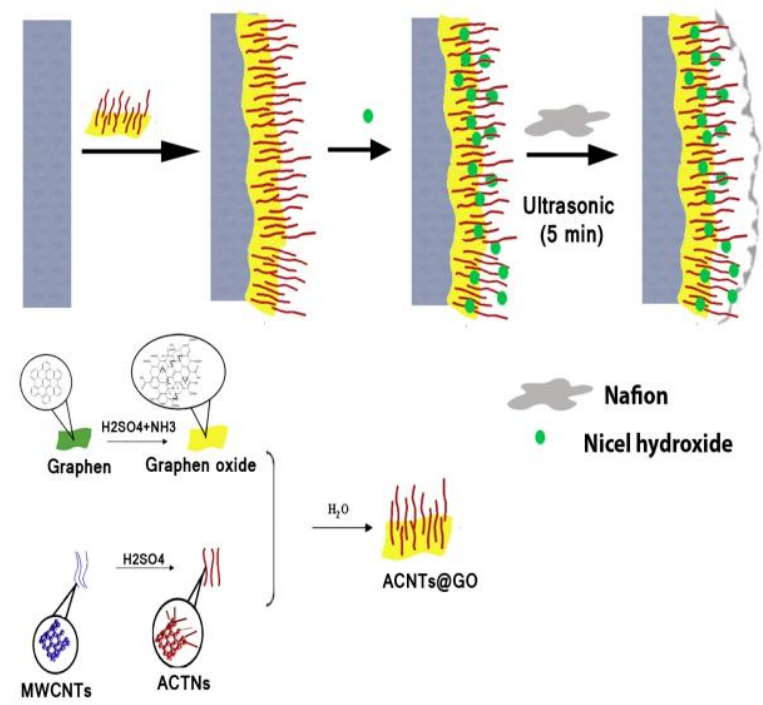

Fig. 1. Schematic illustration of stepwise fabrication process of biosensor: Pt \ACNT@GO\NHNPs\Nf 

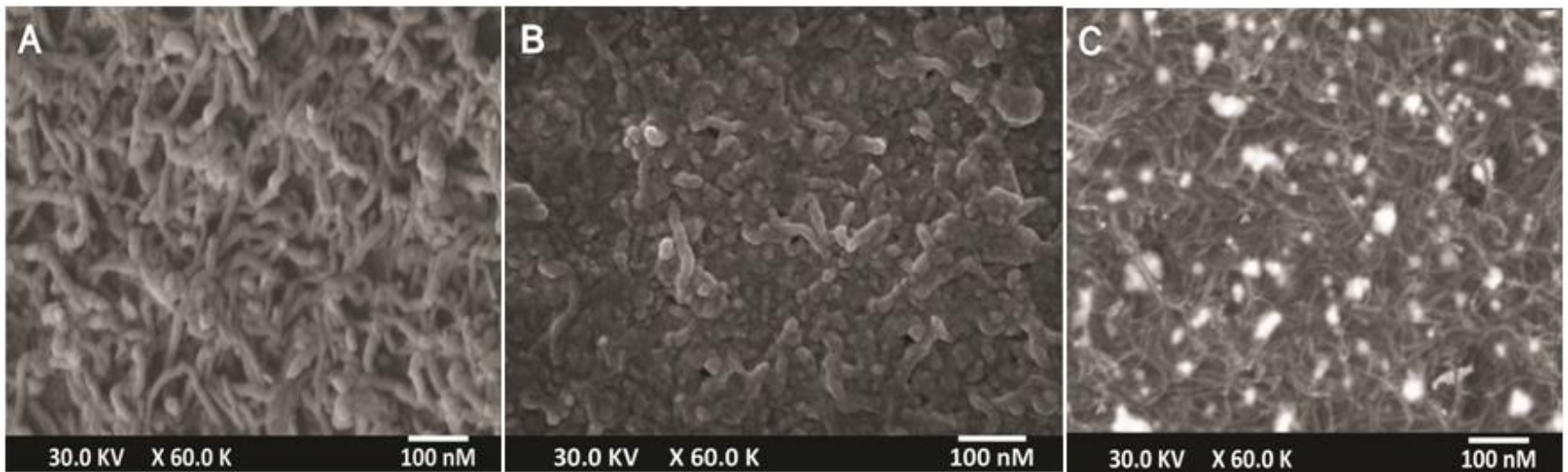

Fig. 2. SEM images of the ACNT (a), ACNT@GO (b) and ACNT@GO\NHNPs on Pt electrode(c)

\section{Result and Discussion}

\subsection{Characterization of the electrode}

NHNPs was characterized by means of TEM. Fig. S1 shows a typical image of the NHNPs synthesized via coordination precipitation method. It can be observed that it appears to have a platelet-like shape and with a dimension of 50-80 $\mathrm{nm}$, and weak agglomeration can be seen.

The XRD pattern of the NHNPs is exhibited in Fig. S2 It can be seen that several diffraction peaks appear at $2 \theta$ $=19^{\circ}, 34^{\circ}, 39^{\circ}, 52^{\circ}, 58^{\circ}, 62^{\circ}, 71^{\circ}$ and $74^{\circ}$, which can be indexed to planes ( $\left(\begin{array}{lll}0 & 0 & 1\end{array}\right),\left(\begin{array}{lll}1 & 0 & 0\end{array}\right),\left(\begin{array}{lll}1 & 0 & 2\end{array}\right),\left(\begin{array}{lll}1 & 1 & 0\end{array}\right),\left(\begin{array}{lll}1 & 0 & 2\end{array}\right)$, $\left(\begin{array}{lll}1 & 1 & 1\end{array}\right),\left(\begin{array}{lll}1 & 0 & 3\end{array}\right)$ and $\left(\begin{array}{lll}2 & 0 & 1\end{array}\right)$ of $\beta-\mathrm{Ni}(\mathrm{OH}) 2$ according to JCPDS card no. 14-0117, respectively. Previous reports have indicated that peaks $\left(\begin{array}{lll}0 & 0 & 1\end{array}\right)$ and $\left(\begin{array}{lll}1 & 0 & 1\end{array}\right)$ were especially broad when the nickel hydroxide was more active [20-22]. Delmas and Tessier also considered a correlation between the electrochemical activity and the XRD pattern of nickel hydroxide [21]. Also, another work from Delmas and coworkers determined this type of pattern to be associated with very poorly crystallized nickel hydroxide, denoted as $\beta$ bc (bc: badly crystallized) [23].

This material, obtained by the ageing of $\beta$-nickel

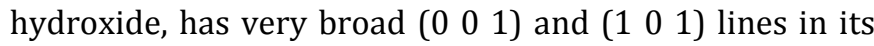
XRD pattern, with narrow (hk0) lines. However the XRD pattern of this sample is very similar to the $\beta b c$-nickel hydroxide. A broadening of the $\left(\begin{array}{lll}1 & 0 & 1\end{array}\right)$ line for NHNPs can be seen, which is ascribed to the disordered structure of the material. Thus, the broadening of the $\left(\begin{array}{lll}0 & 0 & 1\end{array}\right)$ reflection is caused by the smaller crystalline size, as previously reported [24].

In order to study the electrode surface, different parts of the electrode surface were observed by scanning electron microscopy (SEM). Fig. 2 shows a typical image of the ACNT, ACNT@GO and ACNT@GO/NHNPs synthesized through above mentioned methods. The NHNPs shows a platelet-like nanostructure with a dimension in the range of 50-100 nm. It can be seen that, size-homogeneity of these particles is very well.

\subsection{Behavior of Pt $|G O-A C N T \backslash N H N P S| N f$}

In order to investigate the electrochemical properties of Pt $\backslash$ GO-ACNT $\backslash N H N P s-$ modified electrode, cyclic voltammograms were recorded in $0.5 \mathrm{M} \mathrm{NaOH}$ solution. As shown in Fig. 3a, no redox peaks can be seen for Pt in the potential range of 0 to $1 \mathrm{~V}$, indicating that there are no electroactive species to react at this range and the anodic and cathodic peaks of NHNPs in the absence of glucose (Fig. $3 \mathrm{~b}$ are assigned to the $\mathrm{Ni}^{+2} / \mathrm{Ni}^{+3}$ redox couple.

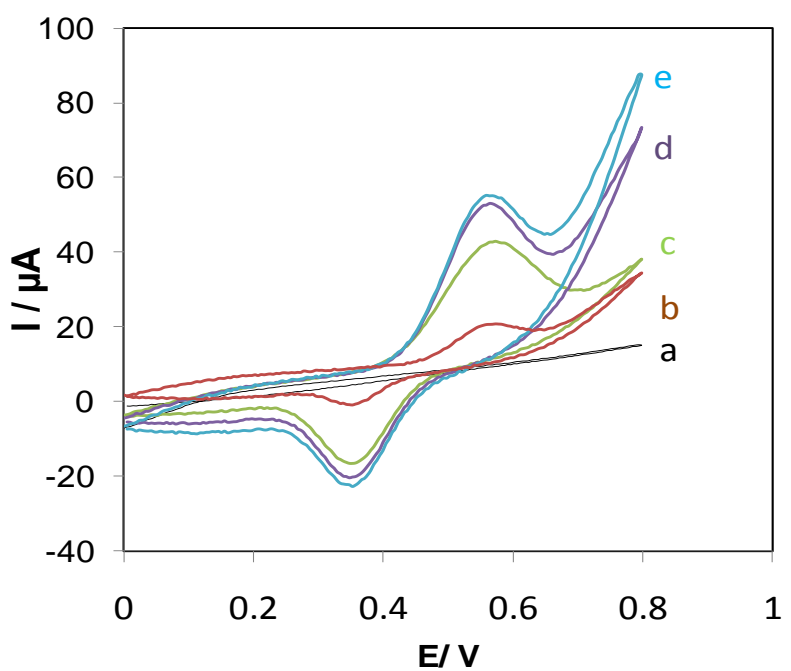

Fig. 3. CVs obtained for in $0.5 \mathrm{M} \mathrm{NaOH}$ solution at (a) Pt, (b) Pt $\backslash$ NHNPs in the absence of glucose, (c) Pt $\backslash$ NHNPs in the presence of $100 \mu \mathrm{M}$ glucose (d) Pt $\backslash A C N T @ G O \backslash N H N P s$ in glucosse and (e) Pt $\backslash A C N T @ G O \backslash N H N P s \backslash N f$ 

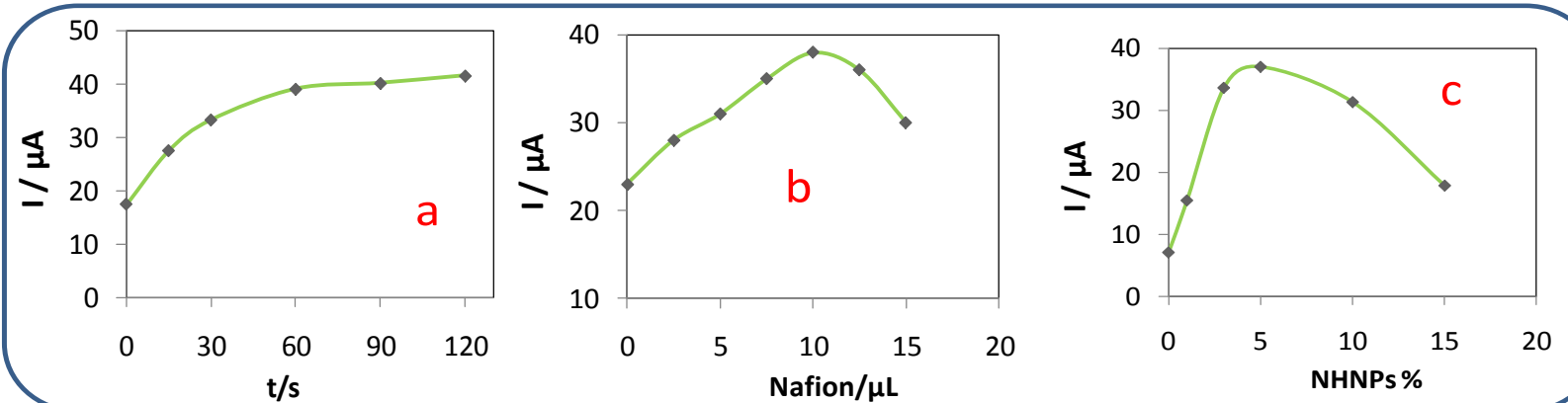

Fig. 4. (a) Effect of the accumulation time, (b) Nafion amount and (c) the ratio of ACNT-GO to NHNPs on the biosensor response. supporting electrolyte, $0.5 \mathrm{M} \mathrm{NaOH}$.

The peak currents increased gradually during successive scans until a steady state was reached. In alkaline solutions NHNPs was oxidized to $\mathrm{NiOOH}$ and turned to $\mathrm{Ni}(\mathrm{OH})_{2}$ by potential cycling [25].

$$
\mathrm{Ni}(\mathrm{OH})_{2}+\mathrm{OH}^{-} \rightarrow \mathrm{NiO}(\mathrm{OH})+\mathrm{H}_{2} \mathrm{O}+\mathrm{e}^{-}
$$

The electocatalytic activity of ACNT@GO \NHNPs modified electrode towards oxidation of glucose in an alkaline solution is shown in Fig. 3c. Upon the addition of glucose, there was a dramatic enhancement of anodic peak current which is attributed to the well-known catalytic effect of the $\mathrm{Ni}^{+2} / \mathrm{Ni}^{+3}$ redox couple for oxidation of glucose to glucolactone according to the following reactions [26] :

$\mathrm{Ni}(\mathrm{OH})_{2}+\mathrm{OH}^{-} \rightarrow \mathrm{NiO}(\mathrm{OH})+\mathrm{H}_{2} \mathrm{O}+\mathrm{e}^{-}$

$\mathrm{NiO}(\mathrm{OH})+$ glucose $\rightarrow \mathrm{Ni}(\mathrm{OH}) 2+$ glucolacton

In the present work, the $\mathrm{Ni}^{+2} / \mathrm{Ni}^{+3}$ species on the electrode surface acts as a catalyst for the oxidation of glucose.

An increase in the anodic peak current and the cathodic peak current after glucose addition is believed to be due to the fact that the $\mathrm{Ni}^{+2} / \mathrm{Ni}^{+3}$ redox couple serves a double function of the electronic medium and catalyst, synchronously[26]. On the other hand, the ACNT@GO mixture was dropped on the electrode could provide a desirable microenvironment to immobilize NHNPs and facilitate the direct electron transfer from it to the underlying electrode (Fig. 3d). Addition of $\mathrm{Nf}$ film, prevent loss of ACNT@GO and NHNPs in solution and improve the anti interferent ability of the biosensor (Fig. 3e)

\subsection{Optimization of Experimental Variables}

The anodic peak currents of glucose improve with accumulation time, but after $30 \mathrm{~s}$ remained almost stable. This may be due to saturation of the amount of glucose adsorbed on the modified electrode surface. Thus, as shown in Fig $4 \mathrm{a}$, the accumulation time of $30 \mathrm{~s}$ was selected as an optimum time for subsequent experiments. The influence of the amount of nafion on the analytical characteristics of the modified electrode is a vital factor affecting the analytical sensitivity of the biosensor. Fig. $4 \mathrm{~b}$ displays the effect of the amount of nafion in the modified electrode. The largest anodic current was achieved when $10.0 \mu \mathrm{L}$ of nafion $5.0(\mathrm{v} / \mathrm{v}) \%$ solutions was used, and it would decrease for increasing volumes of nafion. Modification of Pt electrode with different amounts of ACNT@GO and NHNPs was tested for evaluation the electrochemical response of glucose by cyclic voltammetry. It was found that as the ratio of NHNPs increased from 2 to $5 \%$, the response of electrode improved and when the ratio was more than $5 \%$, the response decreased with larger background current, which is attributed to an increase in the resistance and double layer capacitance of the modified electrode, as a consequence of the decrease in the ratio of ACNT@GO and resulted in poor measure for Glucose (Fig. 4c). Therefore of $5 \%$ NHNPs was chosen for the fabrication of the biosensor.

\subsection{Effect of $p H$ solution}

In most cases, glucose redox behaviour is often significantly dependent on the $\mathrm{pH}$ of solution. The $\mathrm{CV}$ peaks of the modified electrode in $100 \mu \mathrm{M}$ glucose were measured in the $\mathrm{pH}$ range from 8.5 to 13.5 (Fig 5). As shown in Fig. $5 \mathrm{a}$, by increasing the $\mathrm{pH}$ values, the oxidation peak potential shifts to less positive value and the peak current is increased.

Further investigation of the dependence of peak potential upon $\mathrm{pH}$, it is found that there is linear relationship between peak potential and $\mathrm{pH}$, the regression equation is $\mathrm{E}^{0}(\mathrm{~V})=1.255-0.052 \mathrm{pH}$ (Fig. 5b). Since more reproducible results and high catalytic activity of modified electrode was observed at $\mathrm{pH}$ 13.5, we choose $0.5 \mathrm{M} \mathrm{NaOH}$ as electrolyte for glucose determination. 


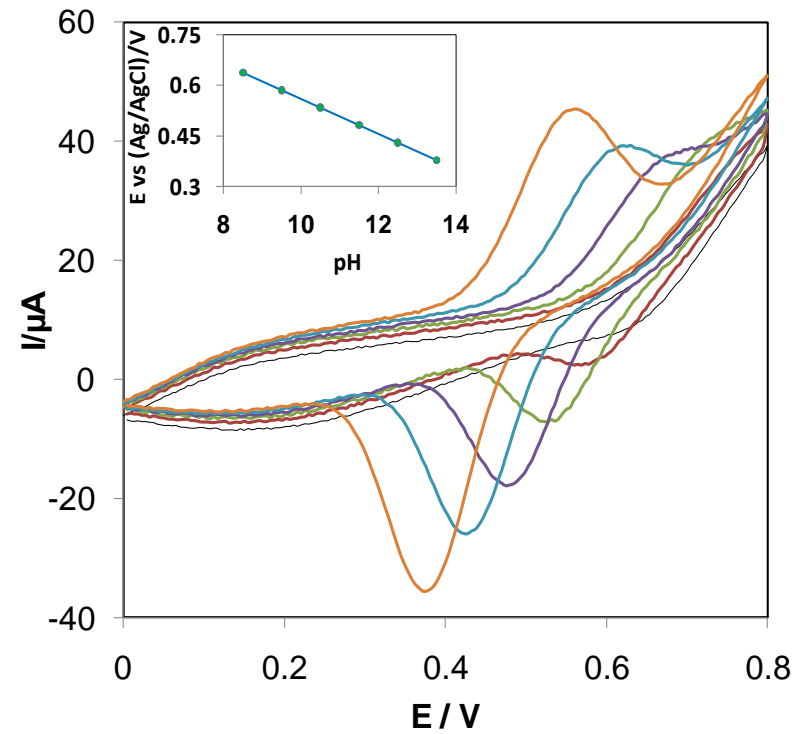

Fig. 5. CVs of Pt $\backslash A C N T @ G O \backslash N H N P s \backslash N f$ in $0.1 \mathrm{M}$ PBs at different pHs. (curves from Right to Left; $\mathrm{pH}=8.5,9.5,10.5,11.5,12.5$, 13.5 ) in the presence of $100 \mu \mathrm{M}$ of glucose and scan rate: $0.1 \mathrm{~V}$ $\mathrm{s}^{-1}$. Inset: Plot of $\mathrm{E}$ vs. $\mathrm{pH}$

\subsection{Effect of the scan rate}

To obtain the kinetic parameters of Modified electrode the effect of scan rate was examined in $0.5 \mathrm{M}$ $\mathrm{NaOH}$. As shown in Fig. 6a, both $\mathrm{Ip}_{\mathrm{a}}$ and $\mathrm{Ip}_{\mathrm{c}}$ increases linearly upon increasing the scan rates from 10 to $400 \mathrm{mV}$ $\mathrm{s}^{-1}$. Fig $6 \mathrm{~b}$, shows the linear relationship between the peak currents versus scan rates. This result indicated that the electrode undergoes a quasireversible electron transfer with the ACNT@GO and NHNPs islands.

It is also found that peak potential varied linearly with the scan, while the formal potential kept almost unchanged. The regression equation was $\mathrm{Epc}=+0.113 \mathrm{log}$ $v+0.66$ with a coefficient of 0.9983 . According to Laviron equation,[27]The relationships of Ep with $\log v$ were calculated and shown in Fig. 6c with two linear equations. Assuming $\mathrm{n}$ is 1 , Form the slope and the intercept, the value of $\alpha$ was got as 0.522 .The electron transfer rate constant (ks) has been calculated using the Laviron Eq.(2) [28] (for $\mathrm{n} \Delta \mathrm{Ep} \leq 200 \mathrm{mV}$ ),

$$
\mathrm{ks}=\alpha \mathrm{nFv} / \mathrm{RT}
$$

An apparent surface electron transfer rate constant, $\mathrm{ks}=2.021 \mathrm{~s}^{-1}$, was estimated. The results also show that the integration of NHNPs and ACNT@GO can provide a remarkable synergistic augmentation of sensor performance. The estimated value is in the controlled range of surface-controlled quasi-reversible process.

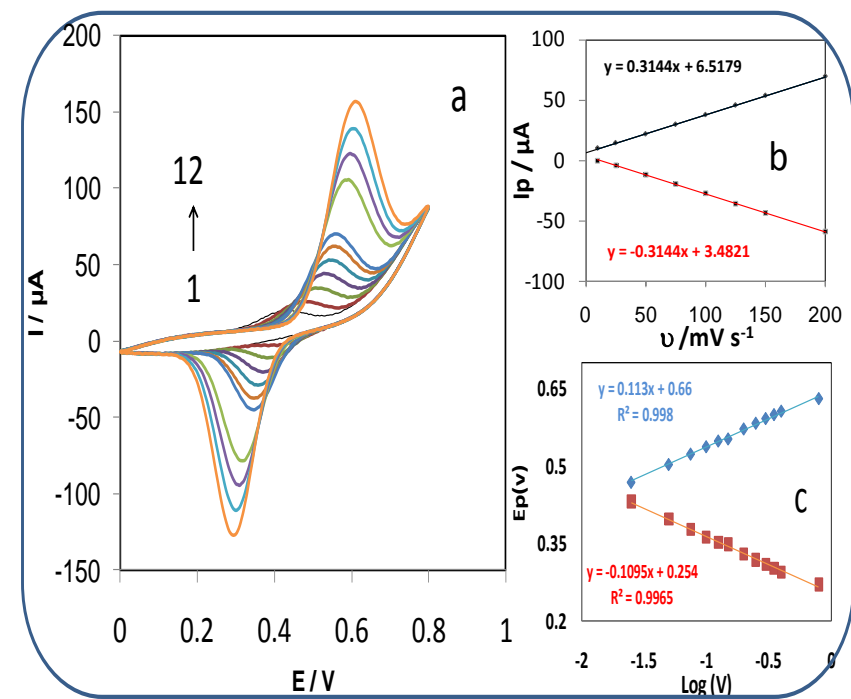

Fig. 6. (a) CVs of Pt \ACNT@GO\NHNPs $\backslash$ Nf at different scan rates (from 1 to 12 ) $0.01,0.02,0.05,0.75,0.100,0.125,0.150,0.200,0.250,0.300$, 0.350 and $0.400 \mathrm{~V} \mathrm{~s}^{-1}$. Insets: (b) dependence of peak currents vs. scan rate, (c) dependence of potential vs. logarithm value of scan rate.

\subsection{Electrocatalytic activity of glucose on the Biosensor}

The electrocatalytic effect of the electrode has also been investigated in the presence of different concentrations of glucose (Fig. 7). As shown, with increasing glucose concentration, the reduction peak currents were increased and the peak potentials were shifted to more negative values. The decrease of overvoltage and increased peak current of glucose reduction confirm that NHNPs film has high catalytic ability for glucose oxidation. The peak currents are proportional to the concentration of glucose and two linear regression equation for the concentration range from 5-100 $\mu \mathrm{M}\left(\mathrm{I}(\mu \mathrm{A})=0.32 \mathrm{C}(\mu \mathrm{M})+5.21, \mathrm{R}^{2}=0.9995\right)$ and 100-1100 $\mu \mathrm{M}\left(\mathrm{I}(\mu \mathrm{A})=0.25 \mathrm{C}(\mu \mathrm{M})+13.95, \mathrm{R}^{2}=\right.$ $0.9990)$ are obtained. The detection limit is estimated to be $0.75 \mu \mathrm{M}$ when the signal to noise ratio is 3 . It can be inferred from these results that the presence of the composite film on the surface of Pt electrode facilitates the detection of glucose at low concentration level. The electrocatalytic reduction of glucose on Pt $\backslash$ ACNT@GO $\backslash N H N P s \backslash N f$ was also studied by amperometry i-t curve. The potential dependence of amperometric signal was tested in the range from 0 to $+1.50 \mathrm{~V}$

The steady-state reduction current increased as the applied potential decreased, which was due to the increased driving force for the fast reduction of glucose at low potential. 


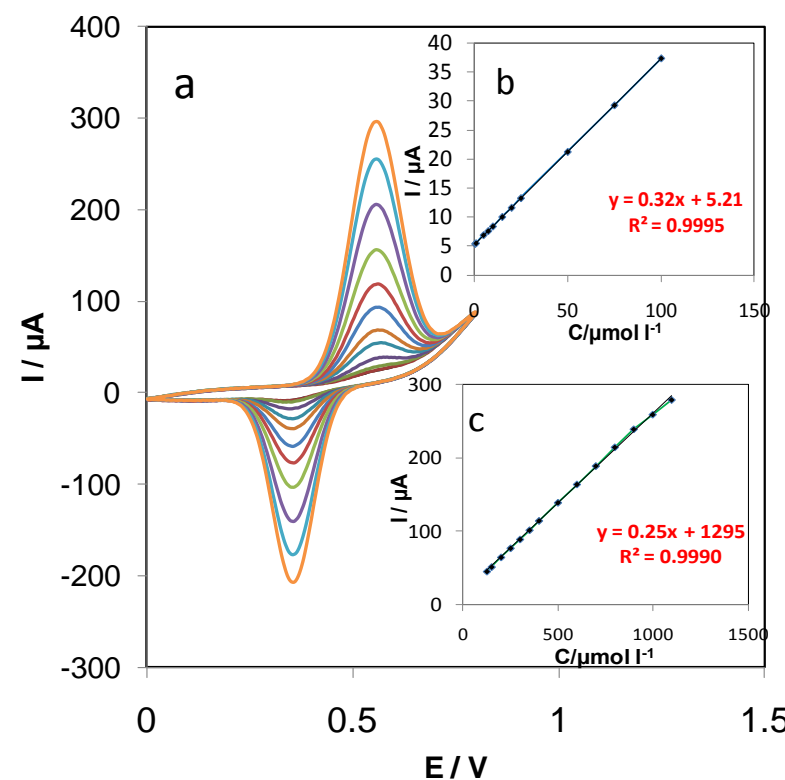

Fig. 7. (a) Cyclic voltammetric response of the biosensor with different concentrations of glucose at a scan rate of $0.1 \mathrm{~V} \mathrm{~s}^{-1}$. The glucose concentrations are as follows: 5, 10, 20, 50, 100, 150, 250, 350, 500, 700, 900 and 1100 respectively, (b) dependence of cathodic peak currents vs. glucose concentration, (c) dependence of anodic peak currents vs. glucose concentration.

So the value of $+0.45 \mathrm{~V}$ was selected as optimum working potential. Fig. 8 and 9 illustrate the typical amperometric response of the glucose sensor at $+0.450 \mathrm{~V}$ on successive step changes of glucose concentration to a continuous stirring $10 \mathrm{~mL} \mathrm{NaOH}(0.5 \mathrm{M})$ solution under the optimized conditions. The modified electrode achieved $95 \%$ of steady-state current within $5 \mathrm{~s}$. This results show that the response time of the sensor is short. The current had a linear relationship with the concentration of glucose. With application of the method two linear ranges were obtained. The first linear dynamic range was from $0.2 \mu \mathrm{M}$ to $24.88 \mu \mathrm{M}$, with a calibration equation of $\operatorname{Ip}(\mu \mathrm{A})=1.32 \mathrm{C}$ $(\mu \mathrm{M})+1.53, \mathrm{R}^{2}=0.9988, \mathrm{n}=10$ and the second linear dynamic range was between $24.98 \mu \mathrm{M}$ to $1800.73 \mu \mathrm{M}$ with a calibration equation of $\operatorname{Ip}(\mu \mathrm{A})=0.943 \mathrm{C}(\mu \mathrm{M})+$ 27.54, $\mathrm{R}^{2}=0.9987, \mathrm{n}=10$. A detection limit of $0.1 \mu \mathrm{M}(\mathrm{S} / \mathrm{N}=$ 3) was obtained.

\subsection{Repeatability and stability of the glucose biosensor}

The biosensor shows good repeatability for the determination of glucose concentration in its linear range. The relative standard deviation (R.S.D.) is $2.8 \%$ for 15 successive assays at the glucose concentration of $10 \mu \mathrm{M}$. The stability of the proposed biosensor was investigated. After 100 cyclic runs, the voltammetric response to $10 \mu \mathrm{M}$ glucose almost remained $94.8 \%$ of the initial response (data not shown). The storage stability of the proposed biosensor was also studied. When not in use, the electrode was suspended above PBS at $4{ }^{\circ} \mathrm{C}$ in a refrigerator. The response to $10 \mu \mathrm{M}$ glucose was tested intermittently. After 7 and 15 days at $4 \circ \mathrm{C}$, the biosensor retained $92.1 \%$ and $90.4 \%$ of its initial response current, respectively.

\subsection{Selectivity of developed glucose biosensor}

The influences of common interfering species in presence of $100 \mu \mathrm{M}$ glucose were investigated, and the results confirmed that interfering species did not significantly influence the height of the peak currents for glucose. The tolerance limit was defined as the maximum concentration of the interfering substance that causes an error less than $10 \%$ for determination of glucose.

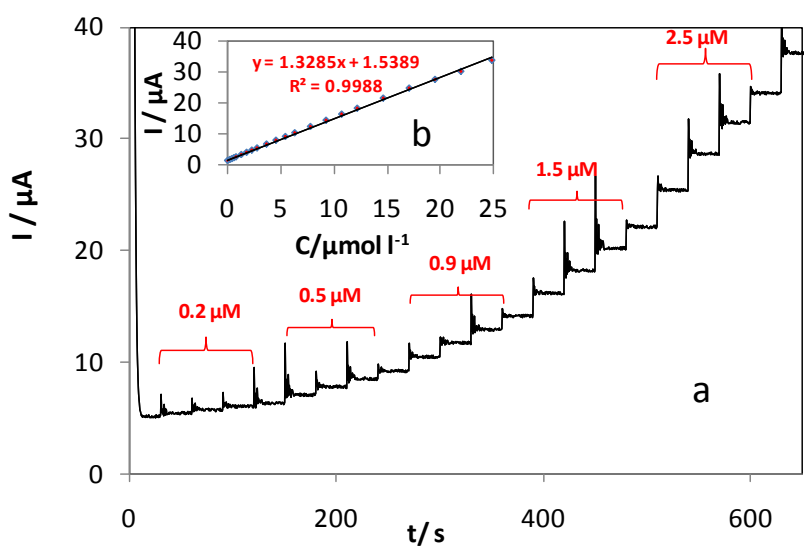

Fig. 8. (a) Amperometric response at a rotating modified Pt (the rotation speed is $1000 \mathrm{rpm}$ ) held at $0.45 \mathrm{~V}$ in $0.5 \mathrm{M} \mathrm{NaOH}$ solution for successive addition of low concentrations of glucose (b) plot of chronoamperometric current response vs. glucose concentration

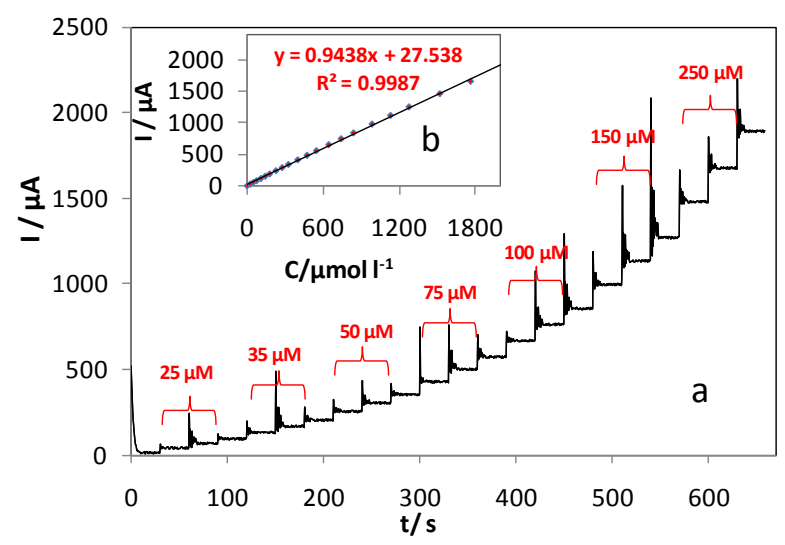

Fig. 9. (a) Amperometric response at a rotating modified Pt (the rotation speed is $1000 \mathrm{rpm}$ ) held at $0.45 \mathrm{~V}$ in $0.5 \mathrm{M} \mathrm{NaOH}$ solution for successive addition of high concentrations of glucose (b) plot of chronoamperometric current response vs. glucose concentration 
The selectivity of the anodic detection of blood glucose is often compromised by the endogenous reducing compounds such as ascorbic acid, uric acid, and acetaminophen, which impose a major issue on nonenzymatic glucose sensors. Negatively charged Nafion has been proposed to be able to eliminate the interference from UA, AA, and ACP[29]. It was found that a 450-fold excess of Uric Acid, 400-fold excess of Ascorbic Acid, 350-fold excess of Acetaminophen, 300-fold excess of Acetic Acid, 250-fold excess of Citric acid, Folic acid and glutamic acid, 200 -fold excess of oxalic acid and Dopamine, 150-fold excess of Sucrose did not interfere with the measurement of glucose.

\subsection{Real sample analysis}

The electrode was next utilized for determination of glucose in human blood serum. Accurate determination of serum levels of glucose is necessary and useful. As a preliminary application in clinical studies, the modified electrode was used to assess the glucose concentrations in healthy human blood samples. Fresh plasma samples were first analyzed by application of a routine enzymatic method (using glucose oxidase) in a local hospital [30] The samples were then reassayed with the Pt $\backslash A C N T @ G O \backslash N H N P s \backslash N f$. The standard addition method was used to complete the experiment. A plasma sample was added into $5 \mathrm{ml}$ PBS ( $\mathrm{pH}$ 13.5), and the response was obtained at $+0.55 \mathrm{~V}$. The contents of glucose in blood can then be calculated from the calibration curve. Results are presented in Table 1 . The results showed that the concentration determined by the proposed sensor is in good agreement with the commercial analyzer. Therefore the fabricated glucose sensor can be useful for the efficient determination of glucose present in the human blood serum samples.

\section{Conclusions}

A specific non-enzymatic glucose sensor was successfully prepared using activated carbon nanotubes @graphene oxide/ nickel hydroxide-Nafion hybrid composite. The modified electrode was fabricated by a layer-by-layer casting method, and the resulting electrode exhibited a good electrocatalytic performance to glucose because of the combining of NHNPs, ACNT and GO. The sensor surface was characterized using FE-SEM, TEM, $\mathrm{XRD}$, and electrochemical techniques.
Table 1. Quantitative results obtained from the analysis of the serum by the purposed method and spectrophotometric method (reference)

\begin{tabular}{|c|c|c|c|c|}
\hline \multirow{2}{*}{$\frac{2}{\frac{0}{3}}$} & Reference & \multicolumn{3}{|c|}{ purposed method } \\
\hline & Glucose $(\mathrm{mM})^{*}$ & $\begin{array}{l}\text { Glucose } \\
(\mathrm{mM})^{*}\end{array}$ & $\begin{array}{l}\text { RSD } \\
(\%)\end{array}$ & $\begin{array}{c}\text { Relative } \\
\text { error } \\
(\%)^{* *}\end{array}$ \\
\hline 1 & 88 & 99.7 & 0.5 & 13.30 \\
\hline 2 & 98 & 100 & 1.6 & 2.04 \\
\hline 3 & 83 & 93.8 & 1.1 & 13.01 \\
\hline 4 & 92 & 108.1 & 1.2 & 17.50 \\
\hline 5 & 91 & 98.2 & 0.9 & 7.91 \\
\hline
\end{tabular}

${ }^{*}$ Average of three measurements

** Deviation between the reference method and the biosensor results.

Comparisons between the analytical characteristics of the proposed electrode with other types of nanocomposite material modified electrode for glucose determination are listed in Table 2. The simple fabrication procedure, high speed, reproducibility, high stability, wide linear dynamic range, low detection limit, high sensitivity, suggest that the proposed biosensor is an attractive candidate for practical applications. In addition, by using nafion polymer layers, the interferences from UA, DA, AA, and other saccharides were avoided. The proposed sensor was successfully applied to the analyses of standard artificial blood and whole blood samples, where the results demonstrated excellent performance compared with a commercial glucose monitoring meters.

\section{Acknowledgments}

The authors gratefully acknowledge the research council of Islamic Azad University-Ilam Branch for providing financial support for this work.

\section{Conflicts of interest}

There are no conflicts to declare.

\section{Appendix A. Supplementary data}

Supplementary data related to this article can be found at http://www.pcbiochemres.com/article_74124.html 
Table 2. Comparison of the proposed electrode for glucose with other types of nano-composite material modified electrode

\begin{tabular}{|c|c|c|c|c|}
\hline Electrode & Method & $\begin{array}{c}\text { linear range } \\
(\mu \mathrm{M})\end{array}$ & $\begin{array}{l}\text { Detection } \\
\text { Limit }(\mu M)\end{array}$ & References \\
\hline PVA/Clay/Hb/CILE & $\mathrm{CV}$ & $7.5-100$ & 2 & {$[31]$} \\
\hline Cat-NiO/PT & $\mathrm{CA}$ & $1-1000$ & 0.6 & [32] \\
\hline $\mathrm{Hb}-\mathrm{CdTe}-\mathrm{CS} / \mathrm{PT}$ & $\mathrm{CA}$ & $7.44-6950$ & 2.23 & [33] \\
\hline Cat-MWCNTs/PT & $\mathrm{CA}$ & $10-100$ & 1 & [34] \\
\hline Mb-SWCNTs-CTAB & $\mathrm{CA}$ & $61.8-507$ & 18.5 & [35] \\
\hline $\mathrm{Mb} / \mathrm{MWCNTs} / \mathrm{Cs} / \mathrm{PT}$ & $\mathrm{CA}$ & $37.9-550$ & NR & [36] \\
\hline Nafion/Mb/IL/PT & CA & $1-180$ & 0.14 & {$[37]$} \\
\hline Nafion/Mb/MWCNTs/CILE & $\mathrm{CV}$ & 8-1960 & 6 & [38] \\
\hline & $\mathrm{CV}$ & $5-1100$ & 0.75 & \\
\hline $\mathrm{Pt} \backslash A C N T @ G O \backslash N H N P s \backslash N f$ & $\mathrm{CA}$ & $0.2-1800.7$ & 0.1 & This work \\
\hline
\end{tabular}

$\mathrm{NR}=$ Not reported, $\mathrm{HRP}=$ horseradish peroxidase, $\mathrm{PVA}$ : polyvinyl alcohol, $\mathrm{CdTe}=$ cadmium telluride nanoparticles, $\mathrm{Cat}=$ catalase, $\mathrm{CTAB}=$ cetyltrimethyl ammonium bromide.

\section{References}

[1] Q. Yi, W. Huang, W. Yu, L. Li and X. Liu. Electroanalysis: An International Journal Devoted to Fundamental and Practical Aspects of Electroanalysis, 2008, 20, 20162022.

[2] J. Zhong, L. Song, J. Meng, B. Gao, W. Chu, H. $\mathrm{Xu}, \mathrm{Y}$. Luo, J. Guo, A. Marcelli and S. Xie. Carbon, 2009, 47, 967-973.

[3] M. Siswana, K.I. Ozoemena and T. Nyokong. Sensors, 2008, 8, 5096-5105.

[4] P. Ajayan. Chemical reviews, 1999, 99, 17871800.

[5] S. Zhang, S. Tang, J. Lei, H. Dong and H. Ju. Journal of Electroanalytical Chemistry, 2011, 656, 285-288.

[6] G. Zhu, Y. Yi, Z. Han, K. Wang and X. Wu. Analytica chimica acta, 2014, 845, 30-37.
[7] A.A. Abdelwahab and Y.-B. Shim. Sensors and Actuators B: Chemical, 2015, 221, 659665.

[8] M. Moreno-Manas and R. Pleixats. Accounts of Chemical Research, 2003, 36, 638-643.

[9] A. Roucoux, J. Schulz and H. Patin. Chemical reviews, 2002, 102, 3757-3778.

[10] T.J. Zhang, W. Wang, D.Y. Zhang, X.X. Zhang, Y.R. Ma, Y.L. Zhou and L.M. Qi. Adv. Funct. Mater., 2010, 20, 1152-1160.

[11] Z. rezayati Zad, S.S. Davarani, A.R. Taheri and Y. Bide. Biosens Bioelectron, 2016, 86, 616-22.

[12] X. Kang, Z. Mai, X. Zou, P. Cai and J. Mo. Anal. Biochem., 2007, 363, 143-150.

[13] C.Y. Liu and J.M. Hu. Biosens. Bioelectron., 2009, 24, 2149-2154.

[14] K. Ohnishi, Y. Einaga, H. Notsu, C. Terashima, N. Rao, S.G. Park and A. 
Fujishima. Electrochem. Solid-State Lett., 2002, 5, D1-D3.

[15] I.G. Casella and M. Gatta. Anal. Chem., 2000, 72, 2969-2975.

[16] E. Shams, A. Babaei, A.R. Taheri and M. Kooshki. Bioelectrochemistry, 2009, 75, 83-8.

[17] Q. Li, L.-S. Wang, B.-Y. Hu, C. Yang, L. Zhou and L. Zhang. Materials Letters, 2007, 61, 1615-1618.

[18] J. Wang, M. Musameh and Y. Lin. Journal of the American Chemical Society, 2003, 125, 2408-2409.

[19] G. Xiao-yan and D. Jian-cheng. Mater. Lett., 2007, 61, 621-625.

[20] K. Watanabe, T. Kikuoka and N. Kumagai. Journal of Applied Electrochemistry, 1995, 25, 219-226.

[21] C. Delmas and C. Tessier. Journal of Materials Chemistry, 1997, 7, 1439-1443.

[22] M.C. Bernard, R. Cortes, M. Keddam, H. Takenouti, P. Bernard and S. Senyarich. Journal of Power Sources, 1996, 63, 247254.

[23] C. Faure, C. Delmas and M. Fouassier. Journal of Power Sources, 1991, 35, 279290.

[24] U. Köhler, C. Antonius and P. Bäuerlein. Journal of Power Sources, 2004, 127, 4552.

[25] P. Luo, S.V. Prabhu and R.P. Baldwin. Analytical Chemistry, 1990, 62, 752-755.

[26] C. Zhao, C. Shao, M. Li and K. Jiao. Talanta, 2007, 71, 1769-1773.

[27] A.J. Bard and L.R. Faulkner. Electrochemical Methods, 2001, 2, 482.

[28] E. Laviron. J. Electroanal. Chem. Int. Electrochem., 1979, 101, 19-28.

[29] J. Wang, D.F. Thomas and A. Chen. Analytical Chemistry, 2008, 80, 997-1004.

[30] O. Giampietro, A. Pilo, G. Buzzigoli, C. Boni and R. Navalesi. Clinical chemistry, 1982, 28, 2405-2407.

[31] N. Hui, R.f. Gao, X.q. Li, W. Sun and K. Jiao. J. Braz. Chem. Soc., 2009, 20, 252-258.

[32] A. Salimi, E. Sharifi, A. Noorbakhsh and S. Soltanian. Biophys. Chem., 2007, 125, 540-548.
[33] Q. Xu, J.H. Wang, Z. Wang, H.Q. Wang, Q. Yang and Y.D. Zhao. Anal. Lett., 2009, 42, 2496 - 2508.

[34] A. Salimi, A. Noorbakhsh and M. Ghadermarz. Anal. Biochem., 2005, 344, 16-24.

[35] H. Xu, H. Xiong, Q.X. Zeng, L. Jia, Y. Wang and S.F. Wang. Electrochem. commun., 2009, 11, 286-289.

[36] L.S. Duan, Q. Xu, F. Xie and S.F. Wang. Int. J. Electrochem. Sci., 2008, 3, 118-124.

[37] A. Safavi and F. Farjami. Anal. Biochem., 2010, 402, 20-25.

[38] W. Sun, X. Li, Y. Wang, X. Li, C. Zhao and K. Jiao. Bioelectrochem., 2009, 72, 170175. 